\title{
Chromosome banding in Podisma pedestris
}

\author{
M. Westerman* and G. M. Hewitt $\dagger$
}

\author{
* Department of Genetics, La Trobe University, \\ Melbourne, Australia. \\ $\dagger$ School of Biological Sciences, University of East \\ Anglia, Norwich.
}

C-banding of $\boldsymbol{P}$. pedestris chromosomes demonstrated the presence of small procentromeric heterochromatic blocks on all members of the complement. The telocentric X-chromosomes and all of the medium sized autosomes also had small distally located $C$-bands and the megarmeric $M_{7}$ chromosome consistently had a number of interstitial bands. The metacentric neo $X$ chromosome found in some populations has a distinctive C-banding pattern in that although the distal C-block of the free $X$ is retained, the centromeric heterochromatin is quite asymetrical with most of the procentric $C$-band of the $X$ apparently having been lost during or subsequent to the $X$-autosome fusion event. Two banding polymorphisms were noted, an extra $C$-band on the $S_{10}$ chromosome and variability in size of the distal C-band on the $M_{6}$. B-chromosomes did not appear to have any $C$-band material other than a small procentric block.

G-banding gave no additional information as the chromosomes appeared light staining only in those regions which were $C$-positive. Use of the fluorochromes Hoechst 33258 and Chromomycin $A_{3}$ showed that the heterochomatin of $P$. pedestris is relatively rich in $\mathrm{G}+\mathrm{C}$ bases.

\section{INTRODUCTION}

In the south western Alps, the wingless montane grasshopper Podisma pedestris is known to exist as two contiguously parapatric sex-chromosome races (John and Hewitt, 1970; Hewitt and John, 1972). A great deal of work has been done on the hybrid zones formed where these two races come into contact (see Hewitt, 1975; Barton and Hewitt, 1981a; Hewitt and Barton, 1981; Halliday et al., 1983). There appears to have been some genetical differentiation between the two races which contributes to the partial inviability of hybrids (Barton and Hewitt, 1981b) and there are small but consistent differences in DNA content (Westerman et al., in preparation) but when cells are stained with orcein there appears to have been little obvious change to the karyotypes other than the X-autosome fusion characterising one race. The present paper describes the application of a number of banding techniques to the mitotic and meiotic chromosomes of $P$. pedestris to define more clearly the basic karyotype and to detect any variations from it.

\section{MATERIALS AND METHODS}

Mitotic metaphases were prepared from embryos immersed in colchicine/saline for 15 minutes and subsequently fixed in 1:3 acetic alcohol. Meiotic preparations were from testes fixed in the field. Air dried slides were made for all staining procedures.

Trypsin G- and $\mathrm{Ba}(\mathrm{OH})_{2} \mathrm{C}$-bandings were carried out using the methods outlined in Webb (1976), slides for C-banding being left overnight on a hot-plate at about $60^{\circ} \mathrm{C}$ prior to treatment.

Hoechst 33258 . This technique basically follows the procedure of Jorgenson et al., (1978) and Schweizer (1976). Preparations were pretreated with Sorensen's buffer ( $p \mathrm{H} \mathrm{6.9)}$ for 5 minutes, stained for 20 minutes in a buffered solution of Actinomycin $C_{1}$ (Sigma, $0.25 \mu \mathrm{g} / \mathrm{ml}$ ) to enhance contrast, rinsed in buffer and prepared for Hoechst staining by soaking in Willard and Latt's buffer for 2 minutes. Slides were then stained with $0.5 \mu \mathrm{g} / \mathrm{ml}$ Hoechst 33258 in Willard and Latt's buffer for 10 minutes, washed, dried and mounted in glycerol. Slides were examined using a Leitz fluorescence microscope with a Ploemak 
illuminator and a Leitz A filter block. Chromomycin $\boldsymbol{A}_{3}$ staining was essentially that of Schweizer (1976). Pretreatment of slides was with McIlvaine's buffer ( $p \mathrm{H} \mathrm{4.9)}$ for 5 minutes followed by staining for 5 minutes in $0 \cdot 1$ per cent Methyl Green (BDH) in buffer ( $p \mathrm{H} 4$-9). Crystal violet was removed from the methyl green counterstain by extraction with chloroform. After rinsing in buffer, the slides were
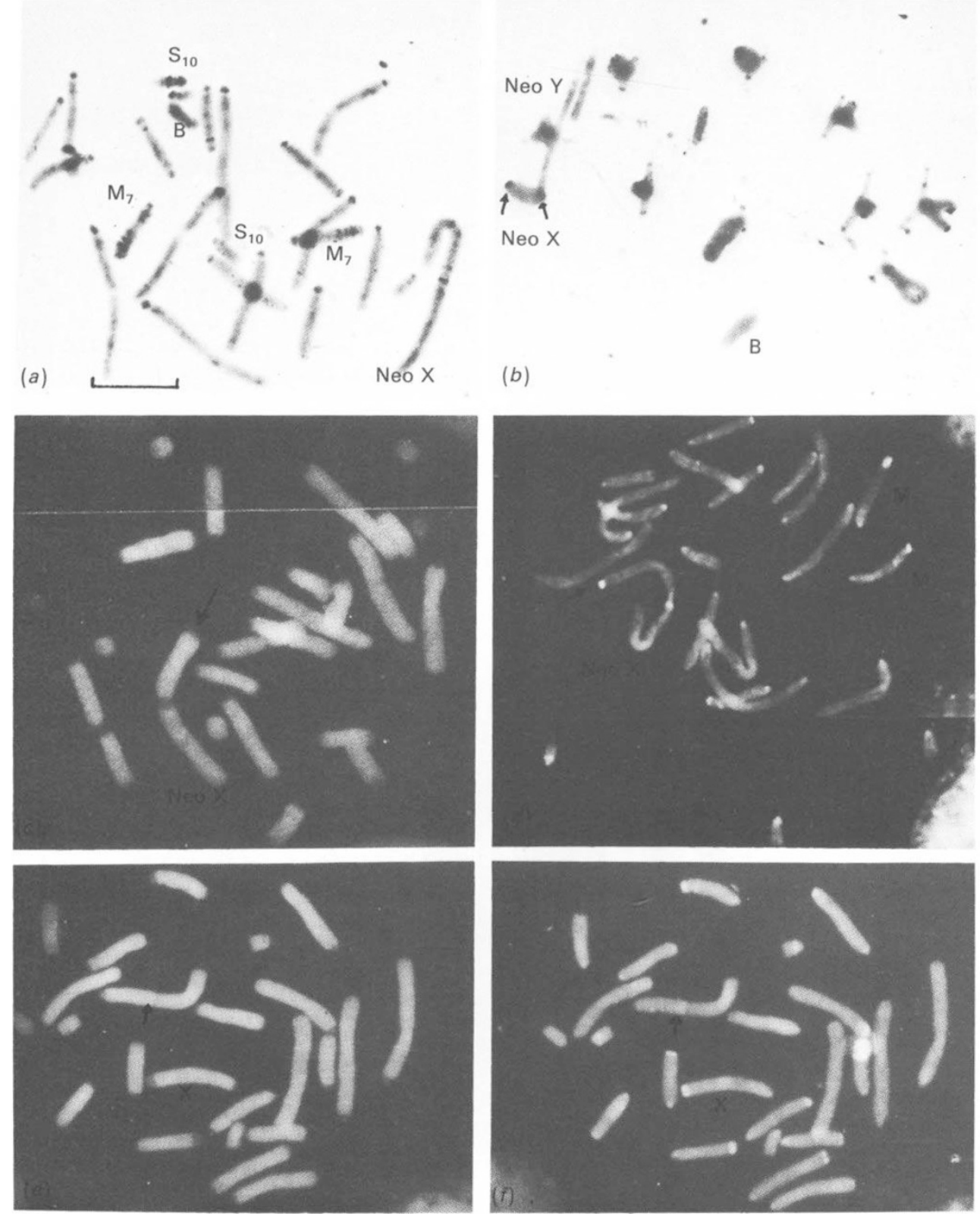

Figure 1 Chromosomes of Podisma pedestris following various staining procedures (a) ( -banded cell from a neo XX female heterozygous for the band on the $S_{10}$ chromosome. A B-chromosome in also present. (b) C-banded meiotic cell from neo $X Y$ male. Note clear C-band on distal end of X arm of neo X. (c) Hoechst 33258 fluorescence of neo XX heterozygote female. Note pale region at distal end of $X$ arm of neo X (arrow). (d) Chromomycin A fluorescence pattern of a neo XX female. This cell is incomplete but note fluorescent hand on distal end of neo X (arrow) and heteromorphism for the distal band on $M_{7}$. (e and f) Fluorescence patterns of a cell from an XX female treated successively with Hoechst 33258 (e) and Chromomycin $\mathrm{A}_{3}$ (f). (arrow indicates light staining band on $\mathrm{L}_{2}$ ). Bar indicates $10 \mu \mathrm{m}$ 
then soaked for 2 minutes in neutral Mcllvaine's buffer ( $p \mathrm{H} \mathrm{6.9)}$ containing $10 \mathrm{mM} \mathrm{MgCl}_{2}$ and subsequently stained with chromomycin $\mathrm{A}_{3}$ (Boehringer, $9 \cdot 25 \mu \mathrm{g} / \mathrm{ml}$ ) for 15 minutes. Washed and dried slides were then mounted in glycerol and stored in the dark for 2 days at $4^{\circ} \mathrm{C}$ to reduce fading of fluorescence during observation which was done using a Ploemak illuminator and a Leitz $\mathrm{E}_{3}$ filter block.

\section{RESULTS AND DISCUSSION}

A C-banded cell from a $P$. pedestris female heterozygous for a normal $\mathrm{X}$ (telocentric) and a neo $X$ (fusion metacentric) chromosome is shown in fig. 1(a). All members of the complement have small pro-centric C-positive regions which correspond to the precocious regions of meiotic chromosomes described by John and Hewitt (1970). In addition, distal C-banding regions are found on all of the medium chromosomes $\left(\mathbf{M}_{4}-\mathbf{M}_{9}\right)$. Two chromosome pairs regularly showed additional Cpositive regions, the $\mathbf{M}_{8}$ which has an extra subterminal band and the $M_{7}$ which is distinctive in having a number of interstitial C-bands. This latter chromosome condenses precociously at meiosis and is similar to the megameric $\mathrm{M}_{7}$ chromosome of Cryptobothris chrysophorous described by John and King (1977). All of the C-bands were apparent on bivalents in male meiosis (fig. 1(b)). The Cbanding pattern is summarised in fig. 2 .

Neo $X$

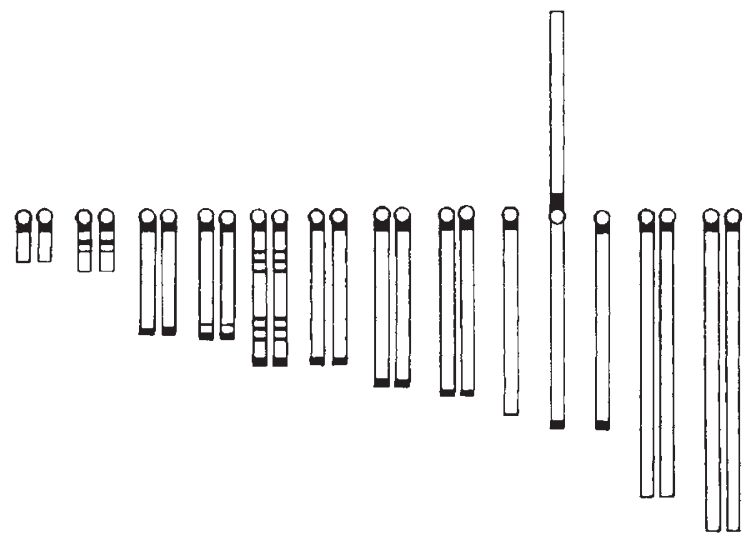

$\begin{array}{llllllllllllll}S_{11} & S_{10} & M_{9} & M_{8} & M_{7} & M_{6} & M_{5} & M_{4} & L_{3} & \times L_{2} & L_{1}\end{array}$

Figure 2 A Karyogram to summarize C-banding in P.pedestris.
The telocentric $\mathrm{X}$ chromosome of hybrids, as in all $\mathrm{XX}$ females and $\mathrm{XO}$ males is characterised by a small procentric and a somewhat larger distal $\mathrm{C}$-band. The neo-X chromosome results from a fusion between a telocentric $\mathrm{X}$ and the third largest autosome $\left(L_{3}\right)$, the fusion event is considered as having taken place "very close to, if not within, the centromere" (John and Hewitt, loc. cit.) This neo $\mathrm{X}$ is characterised by a distinctive C-band on the distal end of the $\mathrm{X}$-arm and by an obvious asymmetry of the centromeric heterochomatin (fig. 1(b), (c), (d)). There is little if any C-band material on the $\mathrm{X}$-arm side of the centromere but a large block of heterochromatin on the autosome arm.

This pattern strongly indicates that the fusion event involved loss of most of the centric heterochromatin from the original X-chromosome (see fig. 3), and that subsequent to the fusion event
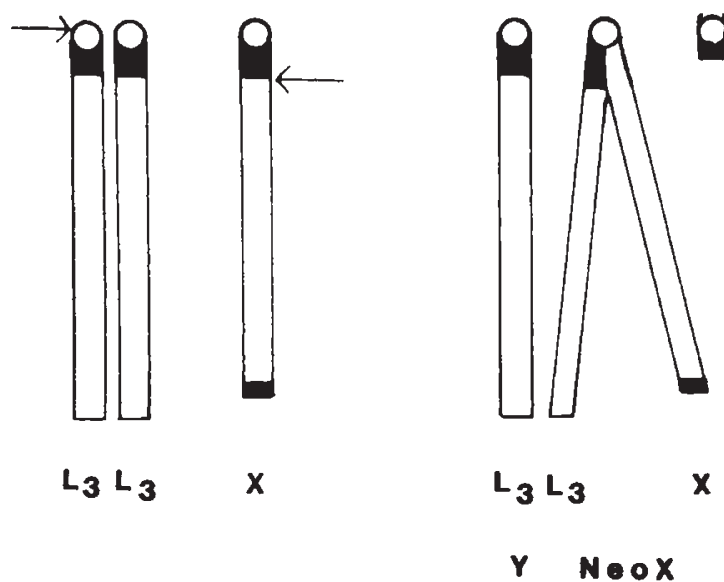

Figure 3 Possible mode of origin of the observed asymmetrical C-banding pattern of the neo $\mathrm{X}$.

there has been an increase in the amount of heterochromatin on the $\mathrm{L}_{3}$ arm. The loss of heterochromatic material from the $\mathrm{X}$ during the fusion event may, in part, explain some of the differences in DNA values between the XO and the neo XY sex chromosome races (Westerman et al., in prep.). Less likely explanations for the observed C.banding pattern are possible, such as the inversion of the large procentric C-band on the $\mathrm{X}$ when the neo $\mathrm{X}$ was formed, but this would involve at least a three break exchange.

Since we know that C-band heterochromatin in Podisma has a different base composition to the rest of the chromosome arm (vide infra) then any alterations in amounts of C-band material must have arisen by duplication or loss of pre-existing 
DNA sequences. Mechanisms capable of accounting for both gain and loss of heterochromatin have been postulated viz., saltatory replication, unequal crossing over, etc. We are thus in a position in this case to exclude from consideration explanations for the altered C-banding pattern of the neo $\mathrm{X}$ chromosome from its constituent components in $\mathrm{XO}$ individuals as being simply due to alterations in the level of coiling of the chromatin.

C-band heterochromatin is one facet of the karyotype in which differences can be detected between species and sometimes between races of the same species (John and King, 1977; John, 1981). In few of these cases can we categorically state whether the direction of change was towards an increase in C-band material or to a decrease. Indeed the general difficulties can be exemplified by Mus musculus molossinus where some chromosomes have consistently less C-band material than their homologues in $M . m$. musculus whereas others consistently have more (Dev et al., 1975). In Podisma pedestris however, we can be fairly sure that the chromosome fusion event involved loss of heterochromatin from the X-chromosome and a subsequent increase in the size of the procentric C-band of the autosome arm.

Three C-band polymorphisms were noted in the material studied:

1. Variable size of the distal heterochromatin on $\mathrm{M}_{7}$.

2. Presence of an additional proximal C-band on $\mathrm{S}_{10}$.

3. Variability of size of the distal C-band on the $\mathrm{X}$-chromosome.

B-chromosomes, which are found in some populations of $P$. pedestris were found to have only a small procentric C-band and thus to be similar in staining pattern to the medium autosomes. In this they are different from the B-chromosomes of $P$. vittatum (Webb and Westerman, 1978) and $C$. terminifera (Webb, 1976) which are greatly Cbanded and distinct from the autosomes.

The G-banding procedures yielded a banding pattern essentially the reverse of that obtained by C-banding with small G-negative procentric regions and light terminal bands on the $M_{4}$ to $M_{9}$ and $\mathrm{X}$ chromosomes. This pattern appears to be general for insect chromosomes (Webb and Westerman, 1978) although a recent technique involving pre treatment of grasshopper embryos with Actinomycin $\mathrm{D}$ has induced longitudinal differentiation of chromosomes after Giemsa staining (Zhan et al., 1984).

The Hoechst 33258 and chromomycin $\mathbf{A}_{3}$ fluorescence techniques were used in order to see if any further differentiation was possible along the mitotic chromosomes as well as to allow some determination of the average base composition of the DNA in the heterochromatic regions. The fluorochrome Hoechst 33258 is known to bind specifically to $A+T$ rich DNA sequences in the chromosome and to enhance fluorescence of these regions under UV illumination (Hilwig and Gropp, 1973; Weisblum and Haenssler, 1974; Comings, 1975). Recent evidence suggests that four consecutive AT pairs are a necessary, but not sufficient, requirement for Hoechst 33258 banding (Martin and Holmes, 1983). The actinomycin- $C_{1}$ counterstain was used to bind and quench regions less rich in $A+T$ 's thus increasing the contrast between areas of different fluorescence. (For a review of counterstain-enhanced chromosome banding, see Schweizer, 1981). Results of this technique can be seen in fig. 1(c), where the heterochromatic C-positive regions fluoresce duller than the rest of the genome.

Chromomycin $\mathrm{A}_{3}$ is known to bind specifically to $\mathrm{G}+\mathrm{C}$ rich regions and thus show brighter fluorescence under UV (Schweizer, 1976). Fig. 1d shows a cell stained with this technique where the centric and distal heterochromatin now fluoresce brighter than the other chromosome regions. The fluorescence pattern of the neo $\mathrm{X}$ chromsome is particulary clear (arrowed). These two fluorescent techniques can be used sequentially on the same slide following rinsing in distilled water to allow direct comparisons on the same cells (fig. 1(e) and 1(f).). The slides can then be C-banded to obtain a permanent record.

It is clear from these results that the C-band positive regions of the chromosomes fluoresce brightly with Chromomycin but dully with Hoechst 33258. This suggests that the heterochromatic regions of $P$. pedestris chromosomes differ in base composition from the rest of the chromosome arms, being relatively richer in $\mathrm{G}+\mathrm{C}$ base pairs. It is also clear that the dull region seen on the $\mathrm{L}_{2}$ chromosomes after both Hoechst 33258 and Chromomycin treatments (see arrows) does not react to the C- or G-banding protocols. The region is most probably a nucleolar organising region though why such a region, normally richer in $\mathrm{G}+$ C's, should fail to fluoresce with chromomycin is not clear.

The $\mathrm{G}+\mathrm{C}$ rich nature of heterochromatin in $P$. pedestris demonstrated by the fluorescence techniques is in contrast to the reported Hoechst bright nature of the centric heterochromatin of three species of the grasshopper genus Dichroplus (Cardoso and Dutra, 1979) and of Spathosternum 
prasiniferum (Das et al., 1979), and to that of the genus Phaulacridium which fluoresce brightly with both chromomycin and Hoechst (Westerman, unpublished data). Such differences in base composition of heterochromatic regions simply underlines the heterogeneity of material covered by this term (John and King, 1977; John and Miklos, 1979).

Acknowledgements. This work was done in part whilst $M$. Westerman was on an Outside Studies Program at U.E.A. Material was collected under a grant from the SERC.

\section{REFERENCES}

BARTON, N., AND HEWITT, G. M. 1981 a. A chromosomal cline in the grasshopper Podisma pedestris. Evolution, 35, 10081018.

BARTON, N. AND HEWITT, G. M. $1981 \mathrm{~b}$. The genetic basis of hybrid variability in the grasshopper Podisma pedestris. Heredity, 47, 367-383.

CARDosA, H., AND DUTRA, A. 1979. The neo X neo Y sex pair in Acrididae; its structure and association. Chromosoma (Berl.), 70, 323-336.

COMINGS, D. E. 1975. Mechanisms of chromosome banding. VIII. Hoechst 33258-DNA interactions. Chromosoma (Berl.), 52, 229-243.

DAS, B. C., RAMAN, R., AND SHARMA, T. 1979. Chromosome condensation and Hoechst 33258 fluorescence in meiotic chromosomes of the grasshopper Spathosternum prasiniferum (Walker). Chromosoma (Berl.), 70, 251-258.

DEV, V. G., MILlER, D. A., TANTRAHAVI, R., SCHRECK, R. R., RODERICK, T. H., ERLANGER, B. F., AND MILLER, O. J. 1975. Chromosome markers in Mus musculus: differences in C-banding between the subspecies M.m.musculus and M.m.molossinus. Chromosoma (Berl.), 53, 335-44.

HALlidAY, B., BARTON, N., AND HEWITT, G. M. 1983. Electrophoretic analysis of a chromosomal hybrid zone in the grasshopper Podisma pedestris. Biol. J. Linn. Soc., 19, 51-62.

HEWITT, G. M. 1975. A sex chromosome hybrid zone in the grasshopper Podisma pedestris (Orthoptera: Acrididae). Heredity, 35, 375-87.
HEWITT, G. M., AND BARTON, N. 1981. The structure and maintenance of hybrid zones as exemplified by Podisma pedestris. In R. L. Blackman, Hewitt, G. M. and Ashburner, M. (eds) Blackwell Scientific Publishers.

HEWITT, G. M. AND JOHN, B. 1972. Interpopulation sexchromosome polymorphism in the grasshopper Podisma pedestris. II Population parameters. Chromosoma (Berl.), $37,23-42$.

HILWIG, 1., AND GROPP, A. 1972. Staining of constitutive heterochromatin mammalian chromosomes with a new fluorochrome. Exp. Cell Res., 75, 122-126.

JOHN, B. 1981. Heterochromatin variation in natural populations. In Chromosomes Today, 7, 128-137.

JOHN, B., AND HEWITT, G. M. 1970. Interpopulation sex chromosome polymorphism in the grasshopper Podisma pedestris. I. Fundamental facts. Chromosoma (Berl.) 31, 291-308.

JOHN, B., AND KING, M. 1977. Heterochromatin variation in Cryptobothrus chrysophorus II. Patterns of C-banding. Chromosoma (Berl.), 65, 59-79.

JOHN, B., AND MIKLOS, G. L. G. 1979. Functional aspects of satellite DNA and heterochromatin. Int. Rev. Cytol., 58, $1-114$.

JORGENSON, K. F., VAN DE SANDE, J. H., AND LIN, C. C. 1978 The use of base pair specific DNA banding agents as affinity labels for the study of mammalian chromosomes. Chromosoma (Berl.), 68, 287-302.

MARTIN, R. F. AND HOLMES, H. 1983. Use of an $I^{125}$-labelled DNA to probe DNA structure. Nature (Lond.), 302, 452454.

SCHWEIZER, D. 1976. Reverse fluorescent chromosome banding with chromomycin and DAPI. Chromosoma (Berl.), $58,307-324$

SCHWEIZER, D. 1981. Counterstain-enhanced chromosome banding. Hum. Genet., 57, 1-14.

WEBB, G. C. 1976. Chromosome organization in the Australian plague locust, Chortoicetes terminifera I. Banding relationships of the normal and supernumerary chromosomes. Chromosoma (Berl.), 55, 229-49.

WEBB, G. C., AND WESTERMAN, M. 1978. G- and C-banding in the Australian grasshopper Phaulacridium vittatum. Heredity, 41, 131-36.

WEISBLUM, B., AND HAENSSLER, E. 1974. Fluometric properties of the bisbenzimidazole derivative Hoechst 33258, a fluorescent probe specific for At concentration inc chromosomal DNA. Chromosoma (Berl.), 46, 255-260.

ZHAN, T, S., PATHAK, S. AND LIANG, J. 1984. Induction of G-bands in the chromosomes of Melanoplus sanguinipes (Orthoptera, Acrididae). Can. J. Genet. Cytol. 26, 354-359. 